\title{
Dichroic Calcite Reveals the Pathway from Additive Binding to Occlusion
}

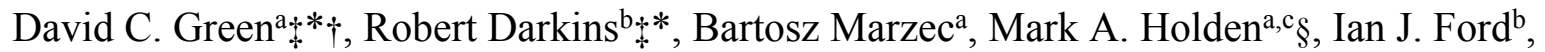 \\ Stanley W. Botchwayd, Bart Kahre, Dorothy M. Duffy ${ }^{\mathrm{b}}$ and Fiona C. Meldrum ${ }^{\mathrm{a} *}$
}

aSchool of Chemistry, University of Leeds, Woodhouse Lane, Leeds, LS2 9JT, United Kingdom. 'bondon Centre for Nanotechnology, University College London, Gower Street, London, WC1E 6BT, United Kingdom. ' $S c h o o l$ of Physics and Astronomy, University of Leeds, LS2 9JT, United Kingdom. ${ }^{\mathrm{d} C e n t r a l}$ Laser Facility, Science and Technology Facilities Council, Research Complex at Harwell, Rutherford Appleton Laboratory, Didcot OX11 0QX, United Kingdom. ${ }^{\mathrm{e}}$ Molecular Design Institute, NYU Department of Chemistry, 100 Washington Square East, New York, NY 10003-6688, United States of America.*F.Meldrum@leeds.ac.uk, R.Darkins@ucl.ac.uk and david.green@hh.se. 


\section{Materials}

Calcium chloride dihydrate, sodium carbonate, sodium bicarbonate, ammonium carbonate, aspartic acid sodium salt hydrate, Congo Red (Sigma-Aldrich, UK); 11-14\% sodium hypochlorite solution (Alfa Aesar, UK), concentrated sulfuric acid, 30\% hydrogen peroxide solution and sodium hydroxide (Fisher, UK) were used as purchased, without further purification. Deionized (DI) water was obtained from an in-house Millipore Reference A+ water purification system (MilliQ, 1-2 ppm OC, $18.2 \mathrm{M} \Omega \cdot \mathrm{cm}$ ).

\section{Methods}

\section{$2.1 \quad$ Stock Solutions}

All stocks were prepared in clean $100 \mathrm{~mL}$ volumetric flasks or by adding $20 \mathrm{~mL}$ DI water to calculated amounts of solid in clean $28 \mathrm{~mL}$ vials capped with plastic lids. Full details are provided in Table S1. $100 \mathrm{~mL}$ solutions were transferred to screw-capped glass bottles for storage. Stock solutions were usable for a few weeks after preparation when stored at room temperature except for $\mathrm{Na}_{2} \mathrm{CO}_{3}, \mathrm{NaHCO}_{3}$ and Asp solutions, which were prepared fresh for each day of experiments.

\subsection{Glass substrates}

Glass cover slips, which are normally used for the preparation of microscope slides for optical microscopy, were cleaned using Piranha solution for $16 \mathrm{~h}$ before rinsing with Millipore water and ethanol and finally dried in a stream of air.

\subsection{Crystal growth protocols}


Ammonia diffusion method (ADM). Calcite/Congo red crystals prepared de novo using the ammonia diffusion method (ADM) were generated by incubating a Petri dish containing an aqueous solution of $10 \mathrm{mM} \mathrm{CaCl}_{2}$ and $20 \mu \mathrm{M}$ Congo red solution in a desiccator containing an atmosphere rich in $\mathrm{NH}_{3}$ and $\mathrm{CO}_{2}$. Infusion of these gases increases the supersaturation of the solution with respect to calcite, and then crystallization occurs via an amorphous calcium carbonate (ACC) precursory phase.

A $40 \mathrm{~mL}$ plastic Petri dish was filled with $30 \mathrm{~mL}$ water and placed into the back of a $5 \mathrm{~L}$ sealable desiccator. A separate $40 \mathrm{~mL}$ plastic Petri dish was filled with ca. $4 \mathrm{~g}$ of $\mathrm{NH}_{4} \mathrm{CO}_{3}$ and covered with Parafilm, which was then punctured 4 times in the centre and placed for $1 \mathrm{~h}$ in the desiccator alongside the water-containing Petri dish. Meanwhile, $1 \mathrm{~mL}$ of $200 \mathrm{mM}$ aqueous $\mathrm{CaCl}_{2}$ solution and $0.2 \mathrm{~mL}$ of $2 \mathrm{mM}$ aqueous Congo red solution were pipetted into a $40 \mathrm{~mL}$ plastic Petri dish and diluted with $18.2 \mathrm{M} \Omega \cdot \mathrm{cm}$ DI water to yield a final aqueous solution containing $20 \mathrm{~mL}$ of $10 \mathrm{mM} \mathrm{CaCl}_{2}$ and $20 \mu \mathrm{M}$ Congo red solution. The Petri dish was equipped with two clean glass substrates, covered with Parafilm, punctured 4 times in the centre, and placed at the front of the desiccator. The desiccator was closed and left for 3 days. After the reaction was complete the crystallization liquor was carefully disposed and the calcite-loaded glass substrates were rinsed with water, bleached with $11-14 \% \mathrm{NaOCl}$ solution for $5 \mathrm{~min}$, and finally washed with an excess of DI water and ethanol.

Calcite seeds required for overgrowth experiments were precipitated following the same protocol, but no organic dyes were added to the growth mixture.

Direct method (DM). Calcite/Congo red crystals prepared de novo using the DM were precipitated in plastic Petri dishes containing an aqueous solution of $\left[\mathrm{CaCl}_{2}\right]=\left[\mathrm{Na}_{2} \mathrm{CO}_{3}\right]=5$ 
$\mathrm{mM}$ and $20 \mu \mathrm{M}$ Congo red. The high $\mathrm{pH}$ and instant availability of carbonate ions in solution lead to high supersaturation conditions with respect to calcite, which precipitated via an ACC precursory phase.

$0.5 \mathrm{~mL}$ of $200 \mathrm{mM}$ aqueous $\mathrm{CaCl}_{2}$ solution and $0.2 \mathrm{~mL}$ of $2 \mathrm{mM}$ aqueous Congo red solution were pipetted into a $40 \mathrm{~mL}$ plastic Petri dish and diluted with $18.8 \mathrm{M} \Omega \cdot \mathrm{cm}$ DI water. Two clean glass substrates were then placed inside the Petri dish and $0.5 \mathrm{~mL}$ of $200 \mathrm{mM} \mathrm{Na}_{2} \mathrm{CO}_{3}$ aqueous solution was added to the reaction mixture, causing the immediate precipitation of calcite crystals. The Petri dish was then covered with a plastic lid, sealed with Parafilm, and left for 3 days. After that time the crystallization liquor was disposed and the calcite-loaded glass substrates were rinsed with water, bleached with $11-14 \% \mathrm{NaOCl}$ solution for $5 \mathrm{~min}$, and finally washed with DI water and ethanol.

Kitano method. Calcite/Congo red crystals prepared de novo using the Kitano method were precipitated in plastic Petri dishes containing a $\mathrm{CO}_{2}$-saturated aqueous solution of $\left[\mathrm{Ca}\left(\mathrm{HCO}_{3}\right)_{2}\right]$ $\approx 10 \mathrm{mM}$ and $20 \mu \mathrm{M}$ Congo red. The low $\mathrm{pH}$ means $\mathrm{CaCO}_{3}$ precipitation is not immediately possible, and only after the effusion of $\mathrm{CO}_{2}$ from solution does the $\mathrm{pH}$ rise sufficiently to yield a solution supersaturated with respect to calcite. This method avoided ACC precipitation, providing a distinctly different reaction profile to the ADM and DM methods described above.

The crystallization liquor was prepared by rapidly bubbling $\mathrm{CO}_{2}$ gas through $100 \mathrm{~mL}$ water containing $\approx 10 \mathrm{~g} \mathrm{CaCO}_{3}$ for $2 \mathrm{~h}$. Immediately after preparation, $20 \mathrm{~mL}$ solution was added through a syringe-driven filter into a Petri dish containing cleaned glass cover slips, where enough volume of Congo red stock solution was added to yield a $20 \mu \mathrm{M}$ Congo red. The Petri dish was then sealed and punctured once to allow the effusion of gas over $16 \mathrm{~h}$. After that time 
the crystallization liquor was disposed and the calcite-loaded glass substrates were rinsed with water, bleached with $11-14 \% \mathrm{NaOCl}$ solution for $5 \mathrm{~min}$, and finally washed with plenty of DI water and ethanol.

Overgrowth method with sodium bicarbonate. Calcite/Congo red crystals were prepared using a variation of the direct method whereby calcite seeds were overgrown with a new layer of calcite by placing them in a supersaturated growth mixture resulting from mixing aqueous solutions of $\mathrm{CaCl}_{2}, \mathrm{NaHCO}_{3}$ and Congo red. 50-100 $\mu \mathrm{m}$ synthetic calcite crystals (Figure $\mathrm{S} 1$ ) were used as seeds in that process. The lower $\mathrm{pH}$ leading to a lower immediate activity of carbonate ions resulted in lower growth mixture supersaturation when compared to the DM- or ADM-based methods.

$0.5 \mathrm{~mL}$ of $200 \mathrm{mM}$ aqueous $\mathrm{CaCl}_{2}$ solution and $0.2 \mathrm{~mL}$ of $2 \mathrm{mM}$ aqueous Congo red solution was pipetted into a $40 \mathrm{~mL}$ plastic Petri dish and diluted with $18.2 \mathrm{M} \Omega \cdot \mathrm{cm}$ DI water. The Petri dish was then equipped with two calcite seeds-loaded glass substrates. $0.5 \mathrm{~mL}$ of $200 \mathrm{mM}$ $\mathrm{NaHCO}_{3}$ solution was added to the growth mixture. The final concentration of reactants in the crystallization mixture was $\left[\mathrm{CaCl}_{2}\right]=\left[\mathrm{NaHCO}_{3}\right]=4,5$ or $10 \mathrm{mM}$ and $[$ Congo red $]=20 \mu \mathrm{M}$. The Petri dish was covered with a plastic lid, sealed with Parafilm, and left for 3 days. After that time the crystallization liquor was disposed and the glass substrates were rinsed with water, bleached with $11-14 \% \mathrm{NaOCl}$ solution for $5 \mathrm{~min}$, and finally washed with ethanol and dried.

\subsection{Analysis of Crystals}

Crystals were analyzed by scanning electron microscopy (SEM) using an FEI NanoSEM Nova 450. Glass substrates supporting crystals were mounted on aluminium stubs with double sided $\mathrm{Cu}$ tape, where the tape was folded to a portion of the top surface of the substrate to minimise 
charging. All samples were coated with a $2 \mathrm{~nm}$ Ir conductive layer prior to analysis. Raman microscopy was conducted on samples produced in the same way using a Renishaw inVia Raman Microscope (785 nm laser) with a 50× objective using MS20 encoded sample stage control through rollerball XYZ peripheral. Data acquisition was undertaken with Renishaw WiRE 3.4 with a laser intensity of $0.1 \%$ under 3 accumulated acquisitions $(3 \times$ scan time $30 \mathrm{~s})$ between 1200 to $100 \mathrm{~cm}^{-1}$. Confocal laser fluorescence microscopy (CLFM) was conducted using a Zeiss LSM510 Upright Confocal Microscope on samples grown directly on clean glass substrates under oil immersion where required. Laser and imaging settings were controlled with Zeiss ZEN software, where conditions tailored for Congo red were used (excitation at $488 \mathrm{~nm}$, low pass emission filter at $550 \mathrm{~nm}$ ).

\subsection{Initial Supersaturations (S)}

Initial supersaturations with respect to calcite, S, were estimated as described in Equation S1, where the activity coefficients were calculated at $298 \mathrm{~K}$ using Visual MINTEQ v.3.

$$
S=\sqrt{\frac{a\left(\mathrm{Ca}^{2+}\right) a\left(\mathrm{CO}_{3}^{2-}\right)}{K_{s p}}} \quad \text { Equation S1 }
$$

Here, $a$ is the activity of the indicated ions and $K_{s p}$ is the solubility product. Carbonate concentrations in $\mathrm{ADM}^{1}$ and $\mathrm{Kitano}^{2}$ were taken from the literature.

\subsection{Liquid Cell Atomic Force Microscope (AFM) Experiments}

AFM images were recorded using a Bruker Multimode 8 with a NanoScope V controller. Images were collected in contact mode using silicon nitride cantilevers with nominal spring constants of $0.35 \mathrm{~N} \cdot \mathrm{m}^{-1}$ (Bruker SNL-10). Rhombohedral calcite seed crystals » $10 \mu \mathrm{m}$ in size were pre-precipitated on glass cover slips under additive-free conditions by mixing equal volumes of $10 \mathrm{mM} \mathrm{CaCl}_{2}$ and freshly prepared $10 \mathrm{mM} \mathrm{NaCO}_{3}$ aqueous solutions. The crystal 
covered glass slide was mounted on an AFM stub, and an appropriately oriented seed crystal was selected. In situ AFM measurements were then collected whilst flowing supersaturated calcium carbonate growth solutions over the seed crystals at $0.3 \mathrm{~mL} \mathrm{~min}{ }^{-1}{ }^{3}$ Fixed calcium concentration and ionic strength AFM growth solutions were prepared by mixing stock solutions of $\mathrm{CaCl}_{2}, \mathrm{NaHCO}_{3}$ and $\mathrm{NaCl}$ in the absence or presence of Congo red. The $\mathrm{NaHCO}_{3}$ solution was prepared fresh, $<2$ hours before use in AFM experiments. Additive-free measurements were made using a growth solution of composition $1.2 \mathrm{mM} \mathrm{CaCl}, 2.4 \mathrm{mM}$ $\mathrm{NaHCO}_{3}$ and $50 \mathrm{mM} \mathrm{NaCl}$. The effect of the additive on growth was investigated by switching to a solution of composition $1.2 \mathrm{mM} \mathrm{CaCl}_{2}, 2.4 \mathrm{mM} \mathrm{NaHCO}_{3}, 50 \mathrm{mM} \mathrm{NaCl}$ and $20 \mu \mathrm{M}$ Congo red. Images were collected at a variety of contact forces in order to image the dye on the surface (low contact force) and the underlying calcite step morphology (higher contact force).

\section{References}

1. J. Ihli, P. Bots, A. Kulak, L. G. Benning and F. C. Meldrum, Adv. Funct. Mater., 2013, 23, 1965-1973.

2. Y. Kitano, Bull. Chem. Soc. Jn., 1962, 35, 1973-1980.

3. H. H. Teng, P. M. Dove and J. J. De Yoreo, Geochim. Cosmochim. Acta, 2000, 64, $2255-2266$. 


\section{Supplementary Tables}

Table S1: Stock solution recipes for all solutions used in this study.

\begin{tabular}{|l|l|l|l|l|}
\hline Material & Method & Volume (mL) & Mass (g) & Concentration (mM) \\
\hline $\mathrm{CaCl}_{2} \cdot 2 \mathrm{H}_{2} \mathrm{O}$ & Volumetric Flask & 100 & 2.940 & 200 \\
\hline $\mathrm{Na}_{2} \mathrm{CO}_{3}$ & Volumetric Flask & 100 & 2.120 & 200 \\
\hline $\mathrm{NaHCO}_{3}$ & Volumetric Flask & 100 & 1.680 & 200 \\
\hline $\mathrm{Congo} \mathrm{Red}$ & Capped Vial & 20 & 0.028 & 2 \\
\hline $\mathrm{NaOH}$ & Volumetric Flask & 100 & 12.00 & 3000 \\
\hline
\end{tabular}


4. Supplementary Figures
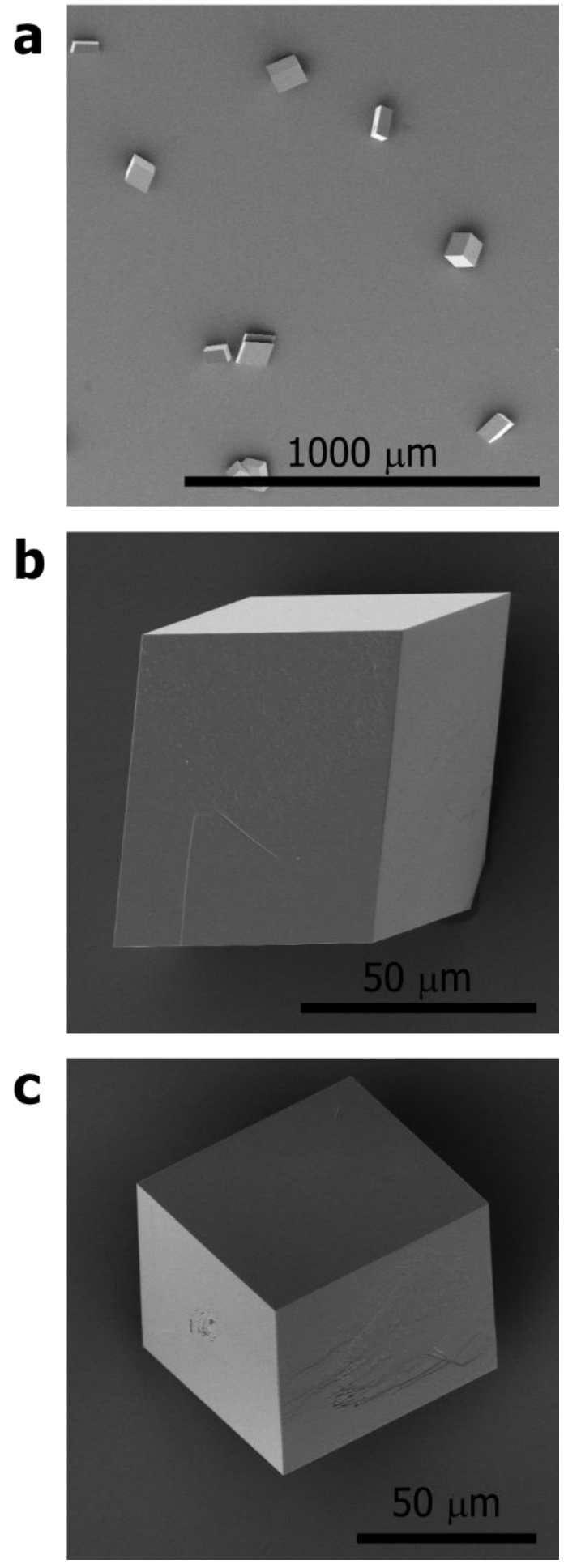

Figure S1. (a-c) SEM micrographs of de novo calcite seeds grown by ADM, shown in general, low magnification view (a), (104)-up oriented crystals (b) and [001]-up oriented crystals (c) are given. 


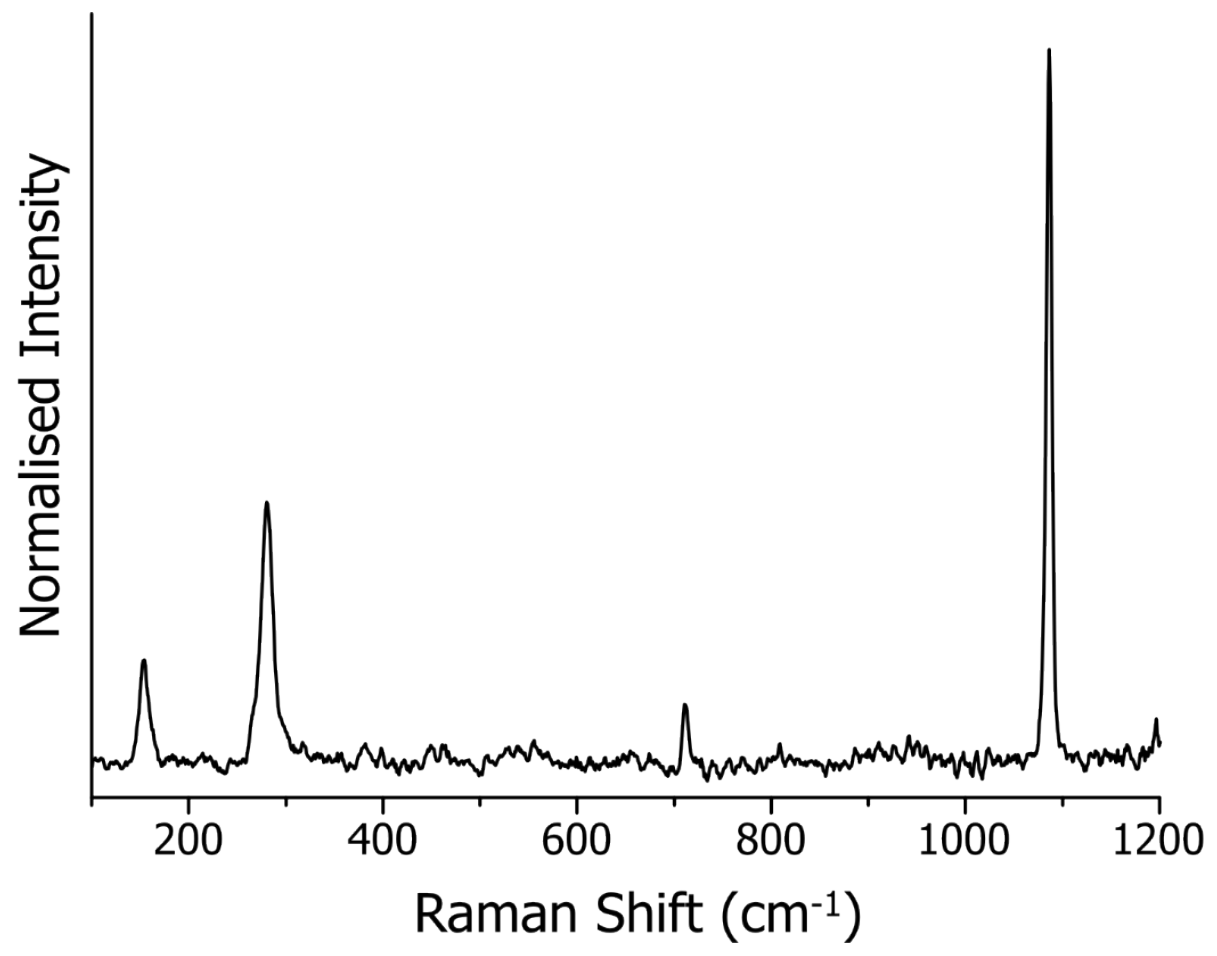

Figure S2. Raman spectrum of $\mathrm{CaCO}_{3}$ (calcite) seeds. 


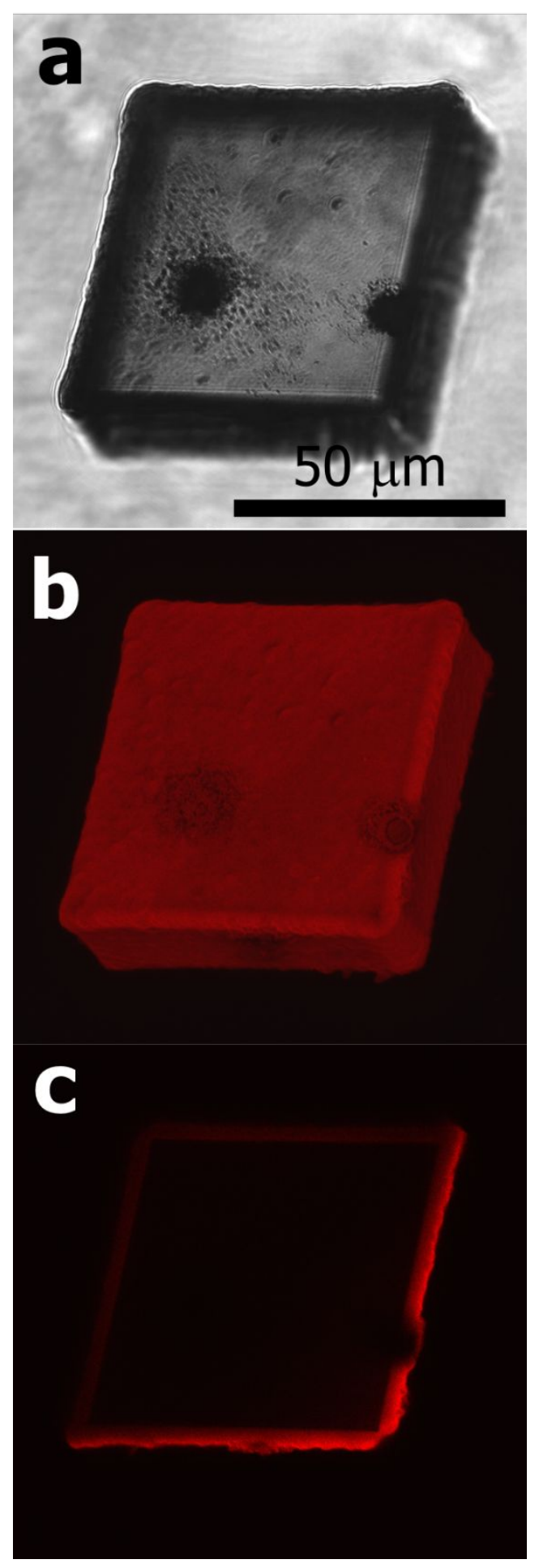

Figure S3. Optical micrograph (a), and 3D stacked (b) and single slice (c) micrographs obtained by confocal laser fluorescence microscopy (CLFM) of calcite seeds overgrown in the presence of Congo red. b reveals the homogeneous coverage of Congo red on all calcite surfaces, whereas c shows the Congo red is confined only into the overgrown sector of the crystal. 
a

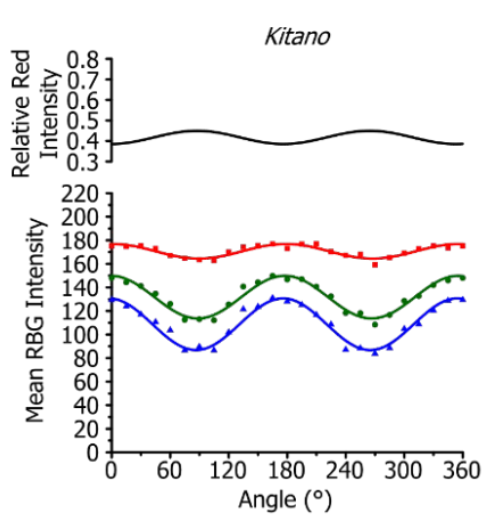

b

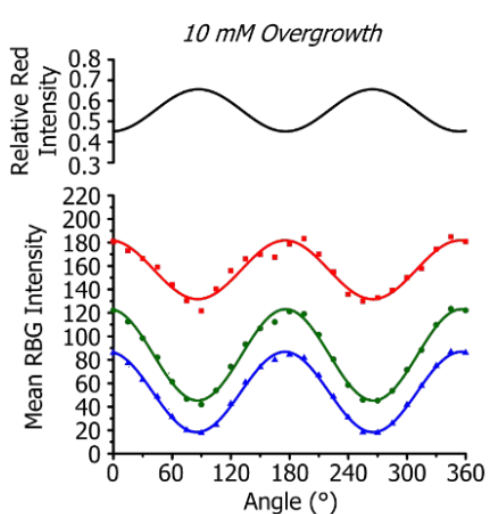

C

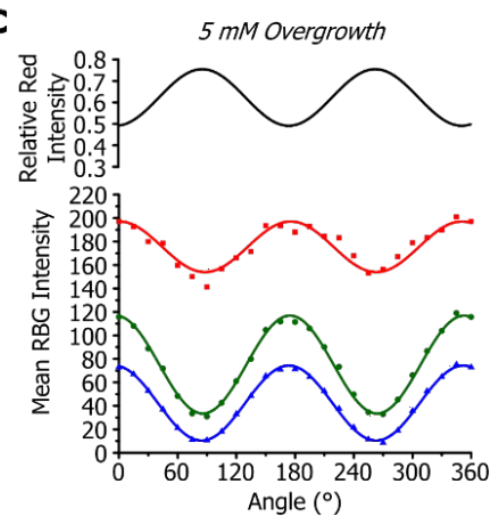

Figure S4. Image analysis (RGB intensities, and relative red intensities calculated using Equation 1, at different angles) plots for calcite grown in the presence of Congo red using various reaction conditions: Kitano (a); and $10 \mathrm{mM}(\mathbf{b})$ and $5 \mathrm{mM}$ (c) overgrowth conditions. 

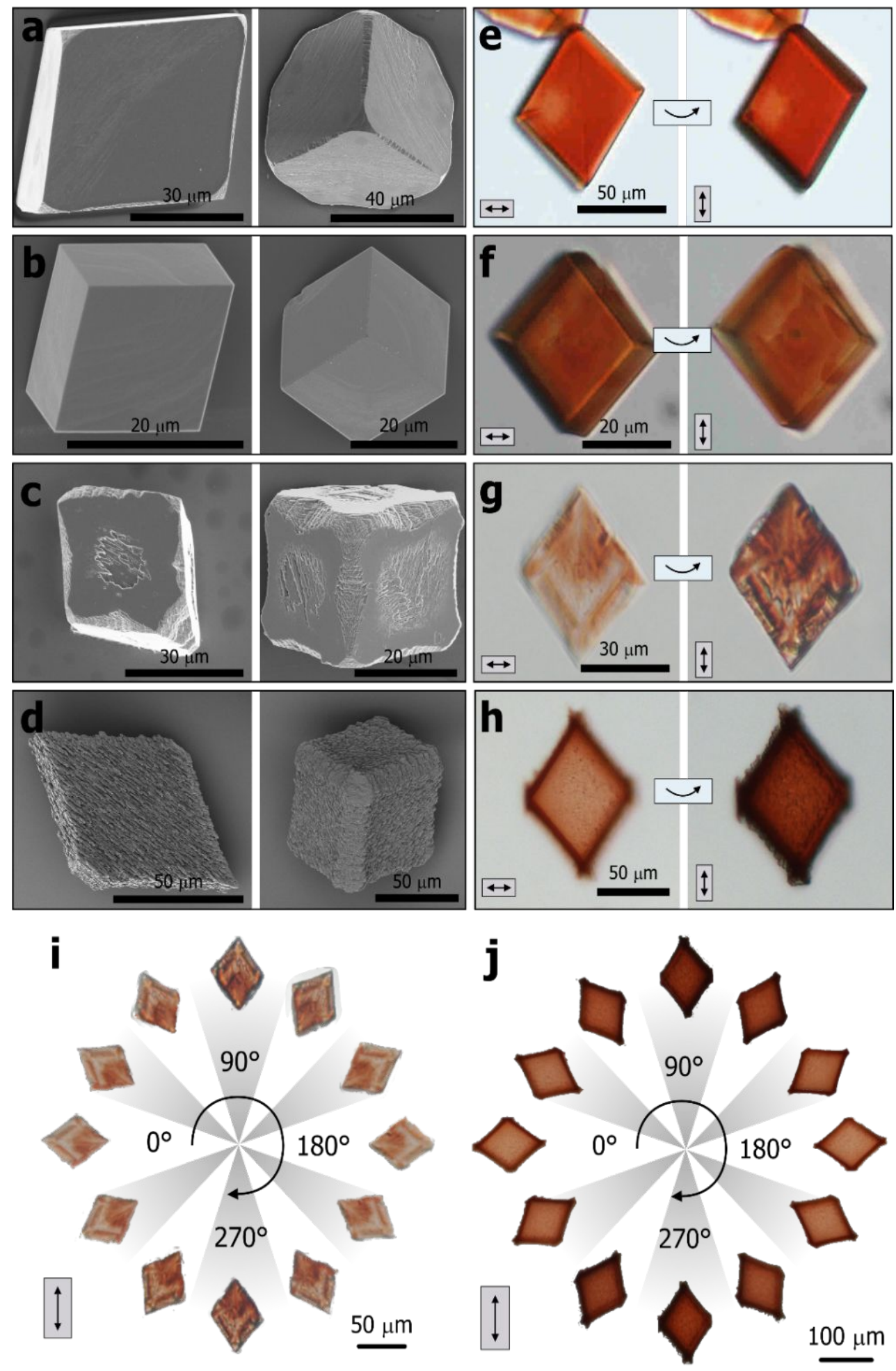

Figure S5. Shape changes and dichroism in Congo red/calcite: (a-d) Scanning electron micrographs of calcite/Congo red crystals grown by ADM (a), DM (b), Kitano (c) and $10 \mathrm{mM}$ overgrowth (d). Micrographs show calcite crystal aligned approximately (104)-up (left) and (001)-up (right). e-h) Optical micrographs of calcite/Congo red crystals grown by ADM (e), 
$\mathrm{DM}(\mathbf{f})$, Kitano (g) and $10 \mathrm{mM}$ overgrowth (e). Micrographs show samples oriented such that calcite's $<010>$ is $0^{\circ}$ (out of plane, left) and $90^{\circ}$ (out-of-plane, right) with respect to the plane of polarized light (boxed black arrow). $\mathbf{i}-\mathbf{j}$ ) optical micrographs of calcite/Congo red crystals grown by Kitano (i) and $10 \mathrm{mM}$ overgrowth $(\mathbf{j})$ growth methods taken at different angles of rotation around a fixed linear polarizer (boxed black arrow), demonstrating the dichroic effect. 


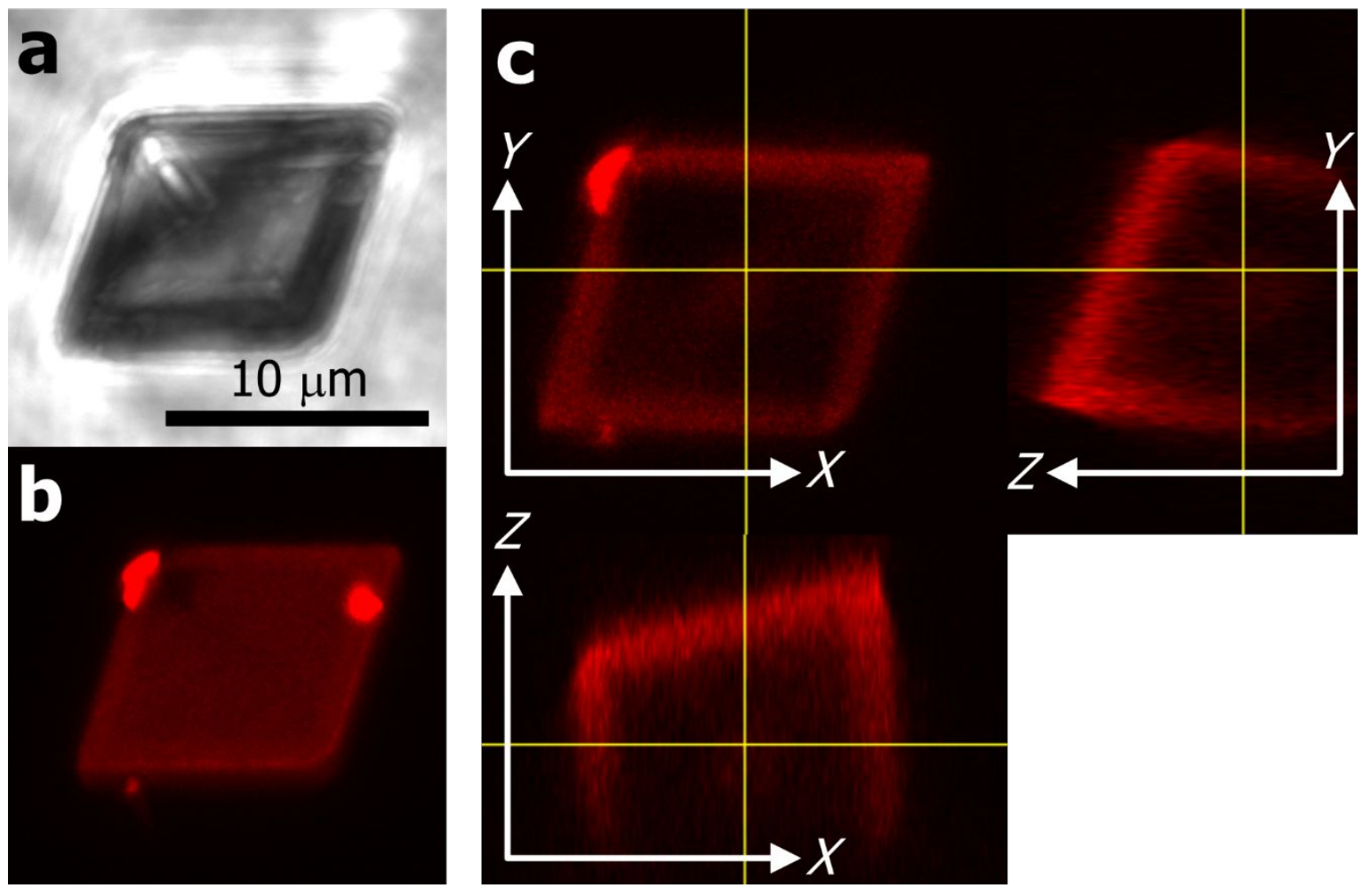

Figure S6. Optical (a) and confocal laser fluorescence (CLFM) (b and c) micrographs of calcite/Congo red nanocomposites prepared using the DM method. The CLFM micrographs are presented as 3D stacked (b) and orthogonal angles (c). In $\mathbf{b}$, the total coverage of Congo red on calcite surfaces is shown, whereas in c, it is possible to see the Congo red distribution throughout the interior volume of a single crystal. 

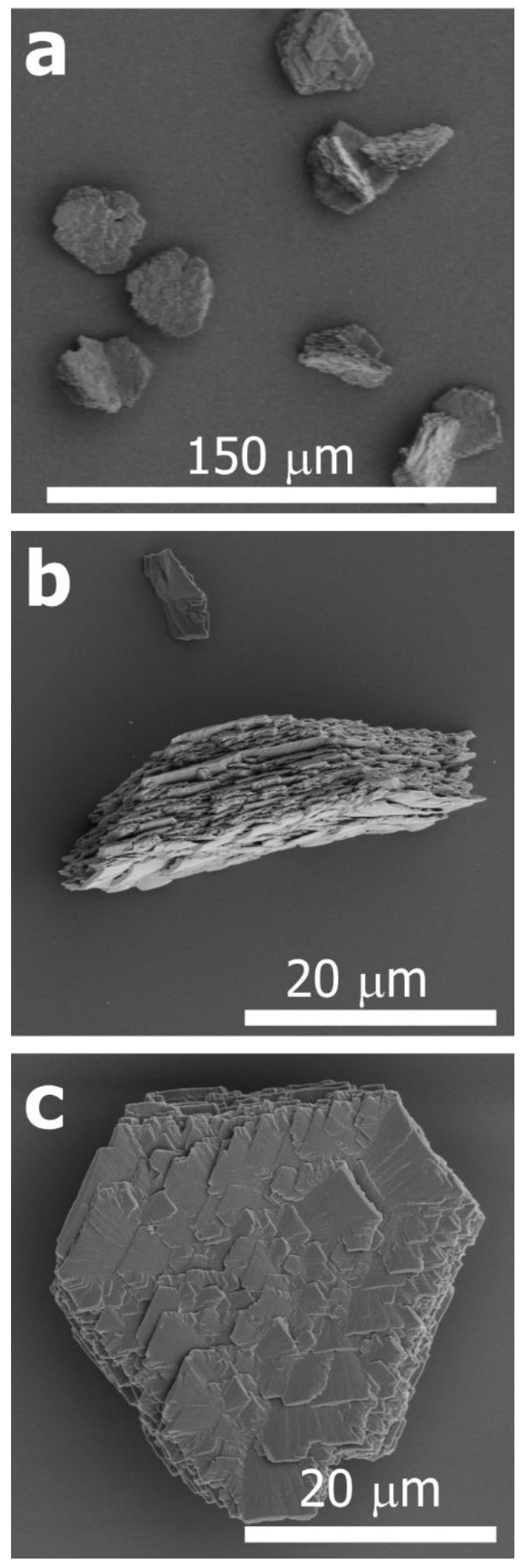

Figure S7. Low (a) and Higher (b and c) magnification scanning electron micrographs of calcite/Congo red nanocomposites grown under DM conditions at [Congo red] $=100 \mu \mathrm{M},[\mathrm{Ca}]$ $=\left[\mathrm{CO}_{3}\right]=5 \mathrm{mM}$; showing the formation of plate-like morphologies due to the higher concentration of Congo red compared to other experiments, where [Congo red] $=20 \mu \mathrm{M}$. 


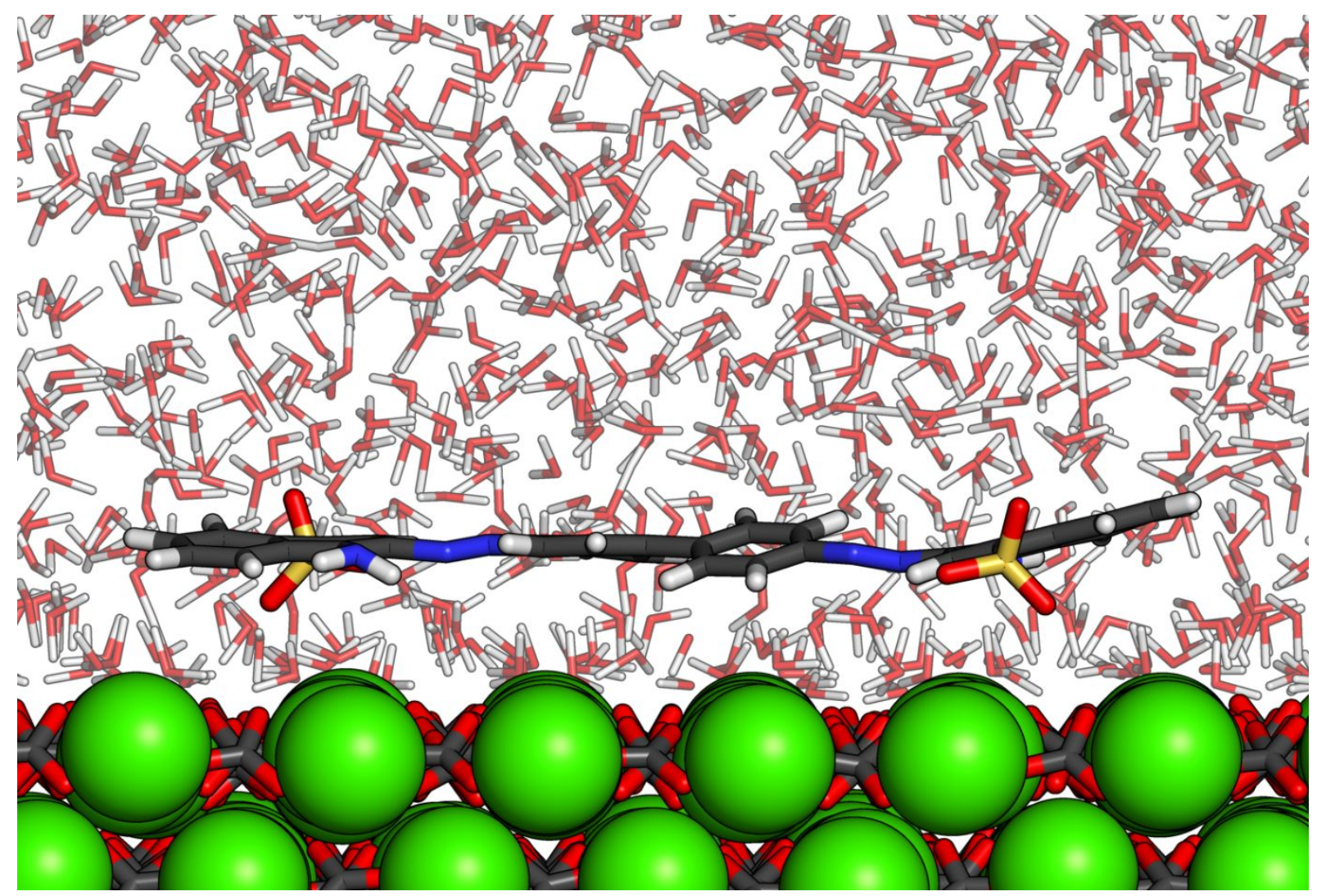

Figure S8. Side-on snapshot of a single Congo red molecule adsorbed at the calcite (104)/water interface (same configuration as Figure 5b). Two hydration layers separate the molecule from the crystal surface. Colors are Ca (green), O (red), S (yellow), C (grey), H (white). 


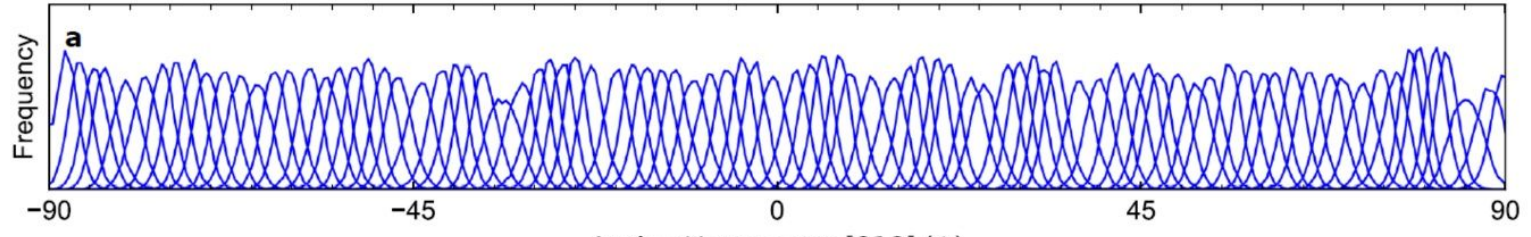

Angle with respect to $[010]\left({ }^{\circ}\right)$

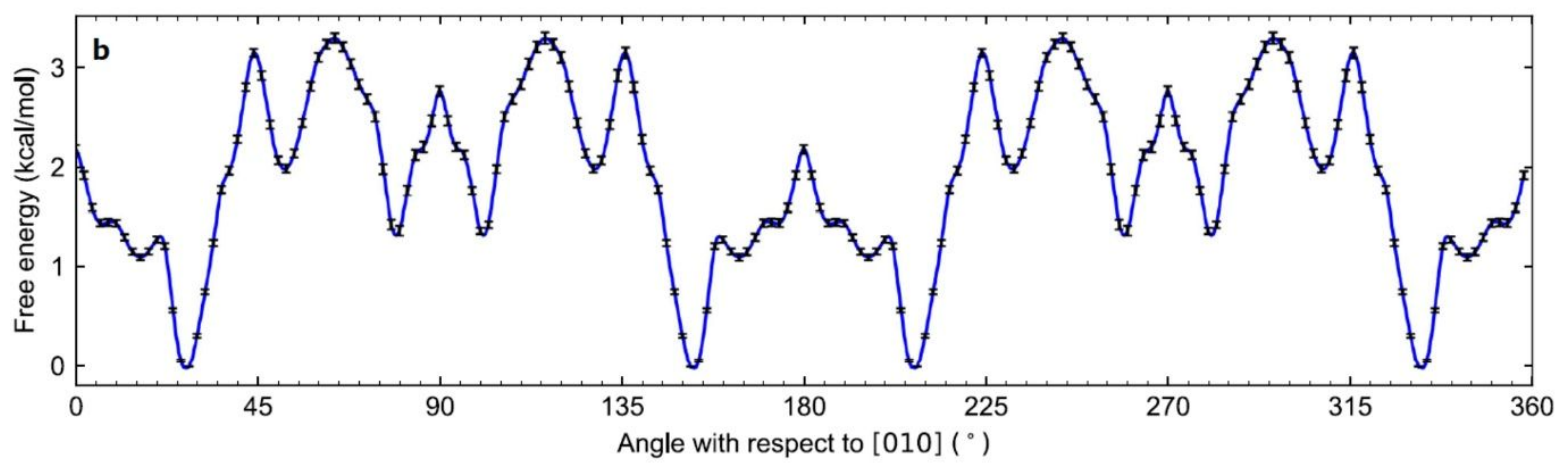

Figure S9. Umbrella sampling results. The raw (normalised) histogram distributions corresponding to each simulation window (a). The resulting free energy curve obtained using WHAM, with sampling errors computed via bootstrap resampling (b). 